\title{
Coefficient of Friction Measured from Nano- to Macro-Normal Loads on Plasma Sprayed Nanostructured Cermet Coatings
}

\begin{abstract}
A.K. BASAK, J.-P. CELIS, M. VARDAVOULIAS, and P. MATTEAZZI
Alumina dispersed $\mathrm{FeCuAl}$-based nanostructured cermet coatings were deposited from nanostructured powders by atmospheric plasma spraying on low carbon steel substrates. Nanostructuring was retained in the deposited coatings which exhibit up to four distinctive phases as revealed by electron microscopy. In this study, the friction behavior of the distinctive phases at nano-normal load scale was investigated alongside their contribution to the overall friction behavior at macro-normal load scale. Friction behavior at nano-normal load scale was investigated by lateral force microscopy, whereas conventional tribometers were used for investigations at micro and macro-normal loads. It appeared that, the friction measured at nano-normal loads on individual phases is dictated by both composition and hardness of the corresponding phases, and thus influences the overall friction behavior of the coatings at macronormal loads. Moreover, the coefficient of friction at macro-normal loads differs from the one at nano-normal loads, and deviates from Amonton's friction law.
\end{abstract}

DOI: $10.1007 / \mathrm{s} 11661-013-2033-\mathrm{Z}$

(C) The Minerals, Metals \& Materials Society and ASM International 2013

\section{INTRODUCTION}

THERMAL sprayed nanostructured cermet coatings are attracting attention due to their enhanced tribological properties. So far, main attention has been given on the synthesis of nanostructured powder and processing of thermal sprayed nanostructured coatings ${ }^{[1-3]}$ together with some investigations on the mechanical and tribological properties. ${ }^{[4,5]}$ Recently, we have reported ${ }^{[4,5]}$ on the superior tribological and mechanical behavior of such nanostructured cermet coatings consisting of a relatively soft nanostructured $\mathrm{FeCuAl}$-matrix and dispersed nanostructured alumina particles, as wear resistant ones, in applications where hardness as well as toughness are essential. The metallic phase in the coating provides toughness, while the ceramic phase increases hardness. Thought the starting powders for plasma spraying consisted of metallic and ceramic nanostructured powders, the resulting coating structure exhibits four different phases of different compositions and hardness. In a preceding investigation on this type of coatings, ${ }^{[5]}$ the focus was on their overall response in tribological behavior with minor attention on its origin. The aim of this work is to carry out a fundamental investigation on the nature of friction recorded on nanostructured coatings which are microstructurally

A.K. BASAK, Duelbeam Engineer, formerly with the Department MTM, KU Leuven, 3001 Leuven, Belgium, is now with Adelaide Microscopy, The University of Adelaide, Adelaide, SA, Australia. Contact e-mail: animeshbasak@yahoo.com J.-P. CELIS, Professor, is with the Department MTM, KU Leuven. M. VARDAVOULIAS, Managing Director, is with the PyroGenesis SA, Technological Park of Lavrion, 19500, Lavrion, Greece. P. MATTEAZZI, Founder and President, is with the CSGI and MBN Nanomaterialia, Via Bortolan 42, Vascon di Carbonera, TV, Italy.

Manuscript submitted July 1, 2013.

Article published online October 4, 2013 non-homogeneous and chemically reactive, and to correlate the friction behavior of individual phases on the overall friction behavior at macro-normal loads. The investigation of friction at nano-normal loads were investigated by lateral force microscopy $(\mathrm{LFM})^{[6]}$, whereas a MUST tester (Falex Tribology N.V.), ${ }^{[7]}$ commercially available tribometer, and a home-made reciprocating sliding tester ${ }^{[8]}$ were used at micro and macro-normal loads.

\section{EXPERIMENTAL}

\section{A. Materials}

Atmospheric plasma spraying (APS) of the coatings was performed by PyroGenesis, Greece, using nanostructured powders supplied by MBN Nanomaterialia, Italy. The nanostructured powders were produced by a Mechanomade ${ }^{\circledR}$ process, ${ }^{[9]}$ which is basically a highenergy ball-milling. These nanostructured powders were then agglomerated by using an organic binder (commercially available) to obtain an agglomeration of about $50 \mu \mathrm{m}$ in diameter. That binder did not induce any physical changes rather than holding the nano-sized powders together as verified by detail characterization of the powder and coating with the help of XRD and TEM. Details of this characterization are available in our previous communications. ${ }^{[4,10]}$ During spraying, the binder phase evaporated (decomposed) due to high processing temperature. The agglomerated nanostructured $\mathrm{FeCuAl}$-alumina powder is mostly irregular in shape (Figure 1). Its overall composition is $32 \mathrm{wt}$ pct Fe, 48 wt pet $\mathrm{Cu}, 2$ wt pet $\mathrm{Al}$ (in total 82 pct metallic phases), and 18 wt pct $\mathrm{Al}_{2} \mathrm{O}_{3}$ (ceramic phase). Details on powder production and characterization, including XRD (Seifert 3003 TT diffractometer) and TEM (Philips CM 300) investigation confirming the retention 


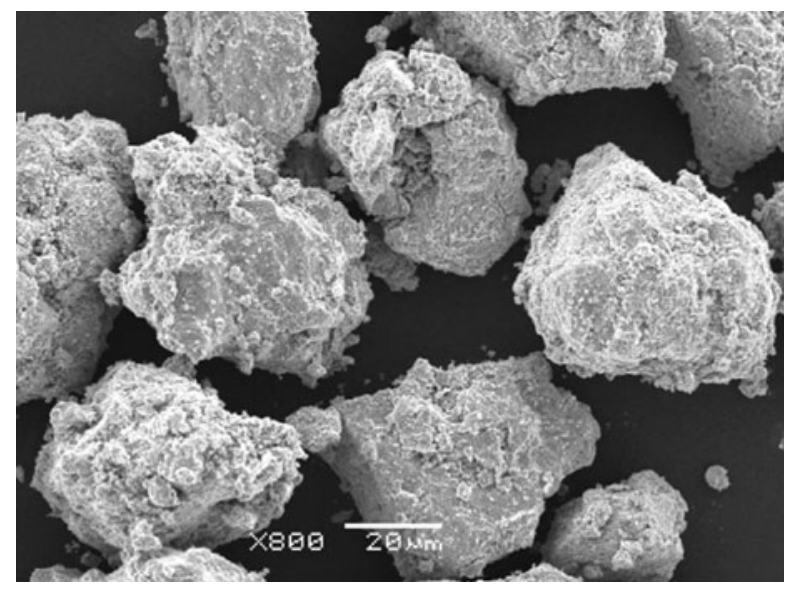

Fig. 1-SEM of agglomerated nanostructured FeCuAl-alumina powder.

of nanostructure in the agglomerated powder, can be found in literature. ${ }^{[4,10]}$

\section{B. Methodology}

Prior to the start of the sliding tests, the coatings were grinded and polished according to standard metallography polishing procedure followed by an ultrasonic cleaning in ethanol for 10 minutes. The average surface roughness determined by non-contact white light interferometry (WYKO NT 3300) was about $40 \mathrm{~nm}$. Three test machines were used to conduct friction experiments, to cover the wide range of normal loads going from nano-Newtons up to Newtons. These equipments were an atomic force microscope equipped with LFM (Nanoscope III, Digital Instruments, USA), ${ }^{[1]}$ a meso-tribometer (MUST ${ }^{\circledR}$ Falex Tribology NV, Belgium), ${ }^{[7]}$ and a macro-tribometer (MTM tribometer) ${ }^{[8]}$ Silicon nitride $\left(\mathrm{Si}_{3} \mathrm{~N}_{4}\right)$ was used as counterbody material in all three test set ups. Calibration of the LFM was carried out on a polished silicon wafer as proposed by Ruan et al. ${ }^{[12]}$ and others. ${ }^{[13,14]}$ A gold-coated triangular cantilever made of silicon nitride with a tip diameter of $20 \mathrm{~nm}$ (provider Vecco ${ }^{\circledR}$ nanoprobe) and stiffness of $0.15 \mathrm{~N} / \mathrm{m}$ was used. The cantilever was moved over the silicon wafer sample at a 90 deg scan angle with respect to the longitudinal axis of the cantilever for measuring the friction force for $2 \mu \mathrm{m}$ peak-to-peak displacements at $1 \mathrm{~Hz}$ sliding frequency. Later, the same procedure was repeated at a 0 deg scan angle. The lateral force signal obtained was converted to friction forces using the calibration procedure developed by Ruan et al. ${ }^{[12]}$ in which they made the assumption that a similar coefficient of friction is valid in all measurement directions. During LFM experiments, the applied normal force was in the range of 20 to $50 \mathrm{nN}$ with $2 \mu \mathrm{m}$ displacement amplitude at $1 \mathrm{~Hz}$ sliding frequency. Each individual set of measurements was performed at five different locations on each phase. This was done to evaluate the spread on the experimental data across the coating surface. Average data are reported and used for data analyses. To make sure that the LFM measurements were done at constant load, the tip shape was constantly monitored qualitatively through adhesion measurements before and after the tests. Indeed in the case of tip-wear, adhesion forces increase due to an increase in contact area.

Since contact pressure is directly proportional to the normal load, and each test equipments has own normal load limitations, the contact pressure was calculated according to Hertzian contact theory. ${ }^{[15]}$ The selection of the size of the counterbody and the normal load to be applied in the different test equipments were done using Eq. [1]:

$$
F_{1 \mathrm{n}} / F_{2 \mathrm{n}}=R_{1}^{2} / R_{2}^{2},
$$

where $F_{1 \mathrm{n}}, F_{2 \mathrm{n}}$ are normal forces and $R_{1}, R_{2}$ are counterbody radii in the macro-tribometer and mesotribometer, respectively. In this work, $R_{1}=5 \mathrm{~mm}$, $R_{2}=2.5 \mathrm{~mm}$ which implies that $F_{1 \mathrm{n}}=4^{*} F_{2 \mathrm{n}} ;$ e.g., $250 \mathrm{mN}$ in the meso-tribometer corresponds to $1 \mathrm{~N}$ in the macro-tribometer which are required to achieve the same maximum contact pressure. Unlike in LFM, the peak-to-peak displacement amplitude was increased to $300 \mu \mathrm{m}$ at $1 \mathrm{~Hz}$ frequency. This means that the friction data arises from a counterbody sliding over more than one phase. That displacement amplitude was chosen to ensure that all the sliding tests took place under gross-slip conditions. All experiments were performed in ambient air of $296.15 \mathrm{~K}\left(23^{\circ} \mathrm{C}\right)$ and 50 pet relative humidity. In this study, friction was investigated by analyzing friction loops obtained by plotting friction force against sliding distance for each sliding cycle. ${ }^{[16]}$ Such friction loops can be recorded in equipment ranging from conventional reciprocating tribometers ${ }^{[7,8]}$ to LFM. ${ }^{[17-19]}$

\section{RESULTS AND DISCUSSION}

\section{A. Coating Characterization}

Representative SEM (Philips XL 30 FEG) micrographs (secondary electron image) of polished cross-section and plan-view on the nanostructured $\mathrm{FeCuAl}$-alumina coating are shown in Figure 2. The structure of coating consists of a matrix and a dispersed high melting point alumina particles. That matrix consists of four distinctive phases notwithstanding that the initial feedstock consisted of metallic (Fe-Cu-Al) and ceramic $\left(\mathrm{Al}_{2} \mathrm{O}_{3}\right)$ powder. EDX analyses (Table I) confirm that the coating is inhomogeneous in composition with the following phases: gray phase (P1) is mainly $\mathrm{Fe}-\mathrm{Cu}$, white phase (P2) is mainly Al-O, and the two composite type phases (P3 and P4) contain both the gray phase (P1) and the white phase (P2) in different ratios. These four phases result from the fact that, agglomerated powders are heated up during thermal spraying, may either melt partially dependent on the melting point of the constituents, undergo plastic deformation, and finally on eventual re-solidification will get a shape and size dictated by the molten materials formed. The somewhat larger grains which are evident in the SEM picture (Figures 2(c) to (f)) are the agglomeration of several nano-sized grains that form during the APS process as a result of grain coalescence at high temperature and 

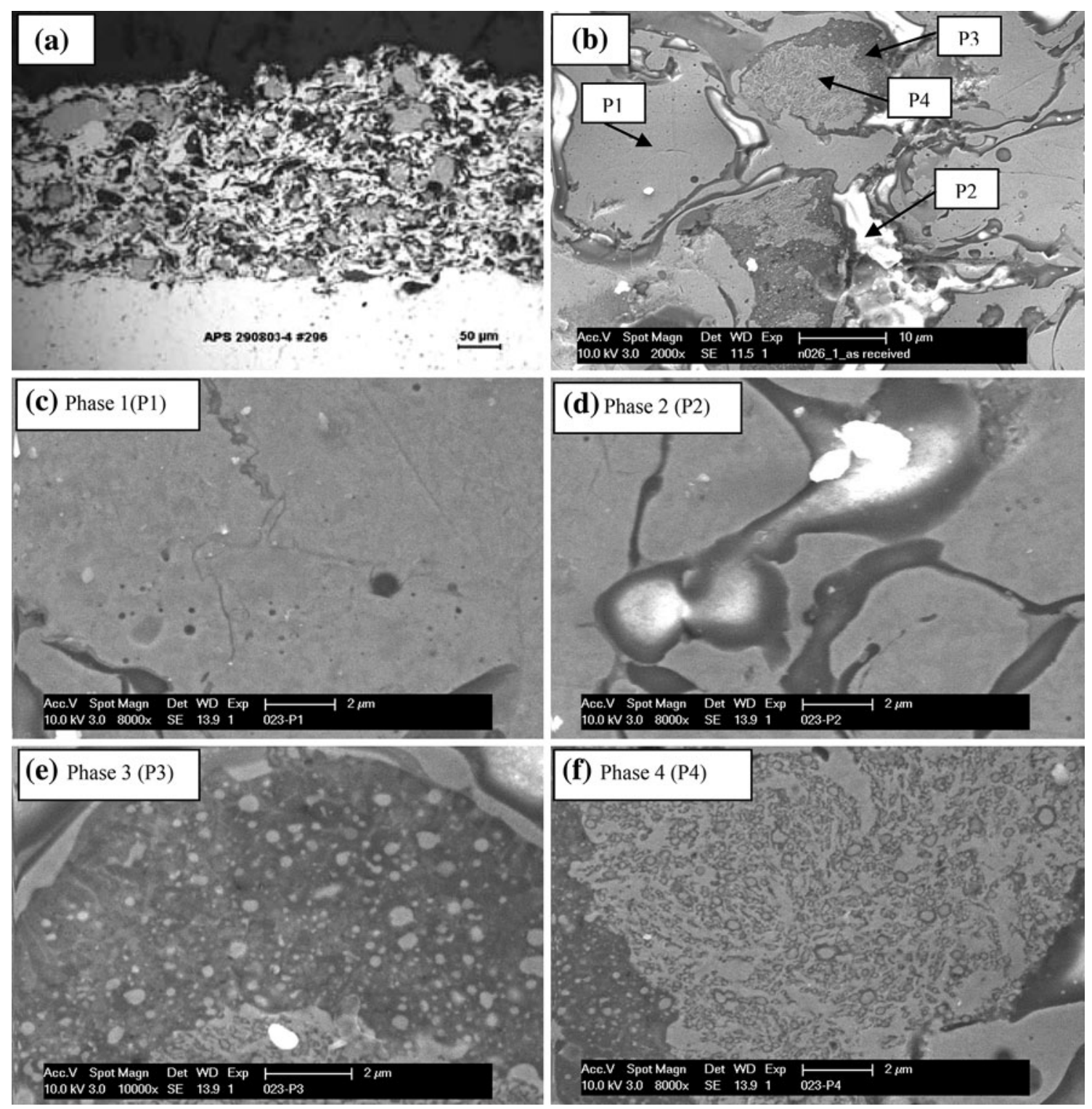

Fig. 2-SEM of metallographic polished nanostructured FeCuAl-alumina coating: $(a)$ cross-section view, $(b)$ plane-view, $(c)$ through $(f)$ enlarged view of phase $1(\mathrm{P} 1)$ to phase $4(\mathrm{P} 4)$ as shown in Fig. $2(\mathrm{~b}) .{ }^{[4]}$

pressure. The estimation of the crystal size in the coatings was done from XRD patterns according to Scherer formula and it is 20 to $50 \mathrm{~nm}$ for $\mathrm{Al}_{2} \mathrm{O}_{3}, 22$ to $28 \mathrm{~nm}$ for $\mathrm{Fe}$, and 20 to $24 \mathrm{~nm}$ for $\mathrm{Cu}^{[4,10]}$ These were further confirmed by AFM and TEM investigation as shown in Figures 3 and 4, respectively. Further EDX analysis in the area shown in Figure 3 conform the abundance of $\mathrm{Al}$ and $\mathrm{O}$ that suggest the presence of $\mathrm{Al}_{2} \mathrm{O}_{3}$. Details on coating characterization including XRD spectra can be found in our previous communications. ${ }^{[4,10]}$

\section{B. Friction Investigation at Nano-Normal Loads}

Friction investigation at nano-normal loads was carried out by a LFM. According to literature, ${ }^{[20-23]}$ the total normal force $\left(F_{\mathrm{N}}\right)$ in nano-contacts results from the sum of adhesion force $\left(F_{\mathrm{adh}}\right)$ and externally applied normal force $\left(F_{\mathrm{n}}\right)$ as expressed in Eq. [2]:

$$
F_{\mathrm{N}}=F_{\mathrm{adh}}+F_{\mathrm{n}}
$$

The external force is $F_{\mathrm{n}}=k Z$ with $k$ the stiffness of the spring and $Z$ the cantilever deflection. The cantilever deflection $Z$ is calculated from the force curve by measuring the deflection corresponding to a particular voltage applied to the cantilever. By changing the piezo voltage, the normal load on the cantilever is varied. The friction on the different phases present in the nanostructured $\mathrm{FeCuAl}$-alumina coatings, the adhesion, and the externally applied normal force were calculated separately as described hereafter.

\section{Adhesion force measurements}

The adhesion force was calculated from the approachretraction curves (force curves) recorded on the different phases in the coatings. A representative force curve 
Table I. EDX Analyses on Nanostructured FeCuAl-Alumina Coating at Locations Indicated in Figs. 2(c) to (f)

\begin{tabular}{|c|c|c|c|c|c|}
\hline \multirow{2}{*}{$\begin{array}{l}\text { Element Detected } \\
\text { by EDX }\end{array}$} & \multicolumn{4}{|c|}{ Phases Identified in the Sprayed Coating (wt pct) } & \multirow{2}{*}{$\begin{array}{l}\text { Overall Sprayed } \\
\text { Coating Composition }\end{array}$} \\
\hline & $\mathrm{P} 1$ & $\mathrm{P} 2$ & P3 & $\mathrm{P} 4$ & \\
\hline $\mathrm{O} \mathrm{K}$ & 1.31 & 43.86 & 34.20 & 15.67 & 14.90 \\
\hline $\mathrm{Cu} \mathrm{L}$ & 27.47 & $*$ & 6.97 & 19.12 & 16.70 \\
\hline $\mathrm{Al} \mathrm{K}$ & 1.12 & 50.43 & 39.37 & 19.79 & 14.14 \\
\hline $\mathrm{Fe} \mathrm{K}$ & 70.10 & 5.71 & 19.46 & 45.42 & 54.26 \\
\hline
\end{tabular}

* Below detection limit.
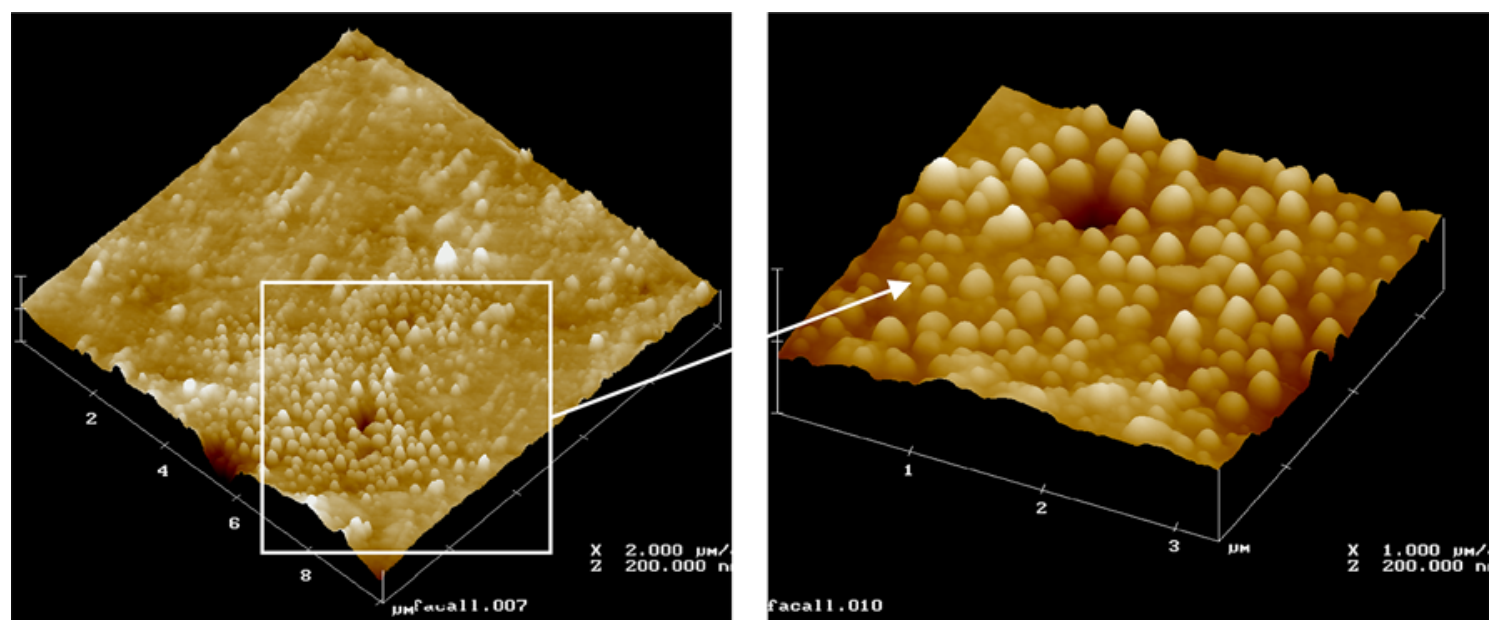

Fig. 3-AFM on polished nanostructured $\mathrm{FeCuAl}$-alumina coating operated in contact mode using a $\mathrm{Si}_{3} \mathrm{~N}_{4}$ cantilever $(0.21 \mathrm{~N} / \mathrm{m}$ stiffness $)$ at phase 3 (Fig. 2(e)).

recorded on phase 1 (Figure 2(c)) is shown in Figure 5. These curves are generated by moving the cantilever toward the substrate, loading it on the substrate, and then slowly pulling it back to its original position. The cantilever deflection is recorded against the vertical scan direction (vertical separation). The dark blue line in Figure 5 corresponds to the downward movement of the cantilever toward the surface (extension or approach), and the black line corresponds to the retraction of the cantilever from the surface. Point "a" in Figure 5 indicates positions where the tip is descending toward the sample and not yet in contact with the surface, that is defined as the zero deflection position. "11] At point "b" a sudden dip in the curve takes place due to a sudden pull down of the tip by attractive forces acting between the nearly touching surfaces. This is known as the jumpto-contact point ${ }^{[1 \mathrm{~T}]}$ and is usually due to electrostatic attraction and/or surface tension. Attraction is also evident between points " $c$ " and " $d$ " on the slopped line corresponding to the step where the cantilever is pulled away from the surface. If the attraction forces are strong, the cantilever will cling to the sample surface as it is pulled clear. Finally point " $e$ " is the pull off point where the tip gets loose from the sample surface and the tip rebounds sharply upward back to the zero deflection position. The adhesion force is calculated by multiplying the distance from the contact segment (point " $d$ ") to the pull off point in the force curve (point " $e$ ") times the cantilever spring constant $(k)$.

\section{Friction force measurements}

During LFM friction force measurements, the torsion signal from the cantilever was recorded during its reciprocating motion across the surface. The forward movement of the cantilever is known as trace and its backward movement along the same path is called retrace. The scan angle in lateral force measurements is kept at 90 deg. The LFM signal plot was converted into tangential force using the procedure proposed by Ruan et $a{ }^{[12]}{ }^{[12}$ Friction force, $F_{\mathrm{f}}$, was measured at an applied normal force varying from $10 \mathrm{nN}$ up to $50 \mathrm{nN}$. Representative tangential $v s$ normal load curves are shown in Figure 6. It was not possible to position the AFM tip exclusively on phase 2 (Figure 2(d)) due to the size of this particular phase and therefore no friction data on phase 2 has been reported here. Linear fits clearly pass through the origin as a consequence of adhesion force correction made to the normal forces. This is in good agreement with the modified Amontons' law proposed by Derjaguin ${ }^{[24]}$ in Eq. [3]:

Friction force, $F_{\mathrm{f}}=\mu \cdot\left(F_{\mathrm{adh}}+F_{\mathrm{ext}}\right)$ or $d F_{\mathrm{f}} / d F_{\mathrm{ext}}=\mu$, 

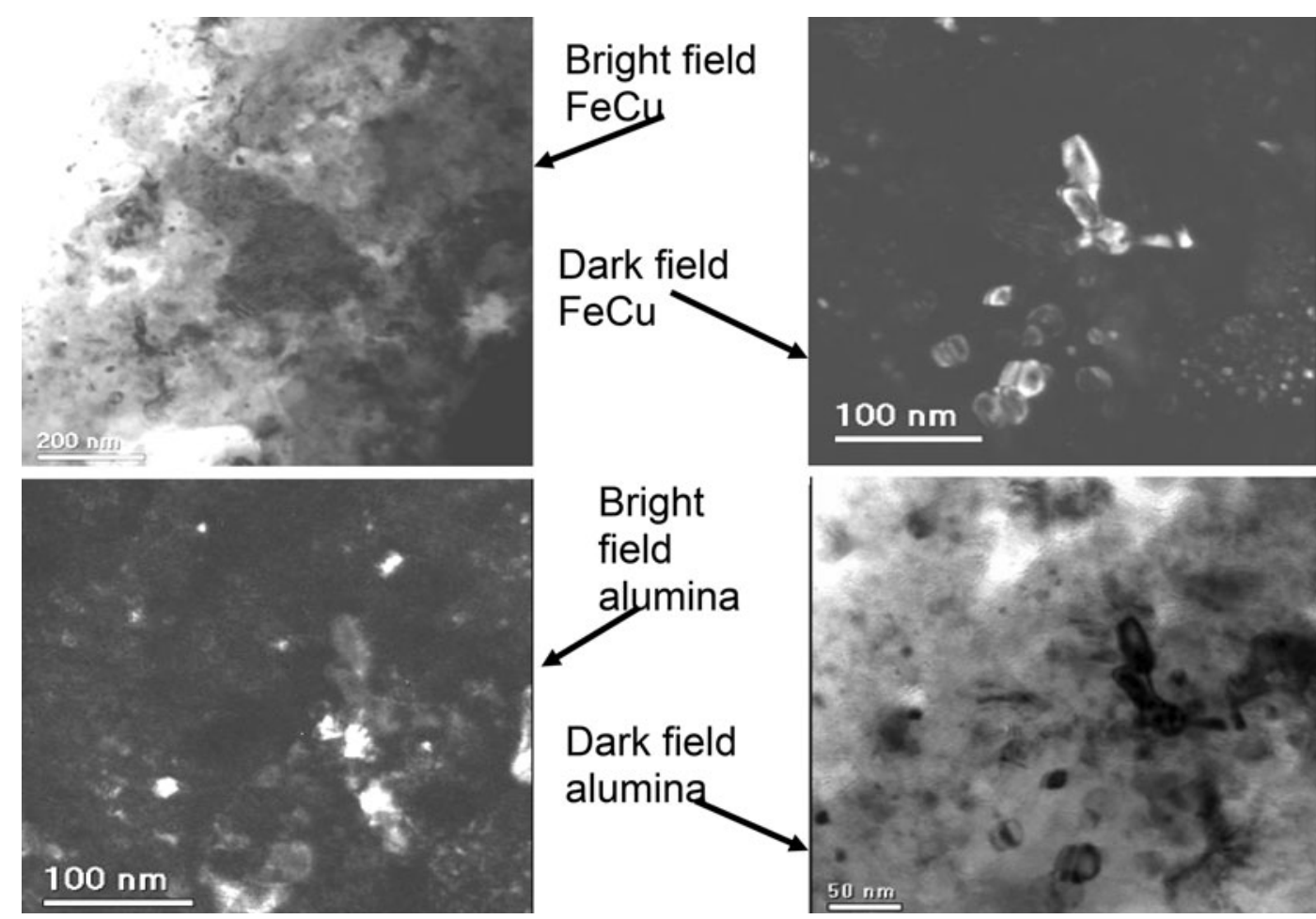

Fig. 4 - Bright field and dark field TEM images of nanostructured $\mathrm{FeCuAl}$-alumina coating. ${ }^{[4]}$

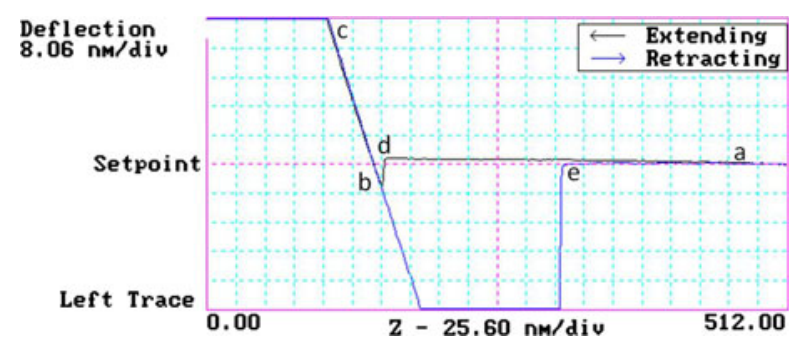

Fig. 5-Adhesion force measurement on phase 1 (Fig. 2(c)) in nanostructured $\mathrm{FeCuAl}$-alumina coating.

where " $\mu$ " is the coefficient of friction. The slope of these linear fits corresponds to the average coefficient of friction (Eq. [2]). The values are reported with 95 pct confidence interval. At nano-Newton normal loads, each phase in the coating exhibits a different coefficient of friction, though they are very close to each other, with the highest value of 0.029 recorded on phase 3 (Figure 2(e)).

It is important to note that at this nano-normal load the friction is greatly influenced by the roughness of the material as well as the surface slope and/or the surface morphology. ${ }^{[25]}$ It was confirmed in this study based on the topography of phase 3 (Figure 2(e)) obtained by AFM (Figure 3), which is an $\mathrm{Al}_{2} \mathrm{O}_{3}$ rich area (as confirmed by EDX) and relatively rough compared to the matrix. The alumina particles are embedded in the matrix and their distribution is not homogeneous which is reflected by a higher coefficient of friction (Figure 6). This is in accordance with nanotribological investigations done by Zhang et al. ${ }^{[26]}$ on MoSx $(x=1.3)$ coatings, and findings of Sundararajan et al. ${ }^{[23]}$ on silicon grids.

\section{Friction Investigation at Micro-Normal Loads}

Reciprocating sliding tests at micro-up to milliNewton normal loads were performed with the meso-tribometer operated in a ball-on-flat contact configuration. The measurement principle of the mesotester is similar to that of a LFM, but it is operated at a different normal load range. The measuring element is a $25 \times 50 \mathrm{~mm}$ cantilever with a tangential stiffness, $k_{\mathrm{t}}$, of $0.214 \mathrm{mN} / \mu \mathrm{m}$, and a normal stiffness, $k_{\mathrm{n}}$, of $0.163 \mathrm{mN} / \mu \mathrm{m} .{ }^{[7]}$ A post-fretting test examination confirmed the absence of any debris in the contact after 25 fretting cycles up to a normal force of $100 \mathrm{mN}$. Beyond that normal force, wear debris are detected in the wear track. Figure 7 shows a typical friction loop obtained during this test. During the experiments, normal load and corresponding tangential force were recorded on-line and the coefficient of friction was calculated accordingly. ${ }^{[7]}$

\section{Friction Investigation at Macro-Force Scale}

Reciprocating sliding tests at macro-forces were carried out in a home-made tribometer ${ }^{[8]}$ operated at a $300 \mu \mathrm{m}$ peak-to-peak displacement amplitude and $1 \mathrm{~Hz}$ sliding frequency. Like in the case of the meso-tribometer, the normal load and tangential force were recorded on-line and the coefficient of friction was calculated accordingly. In this case, wear of the 


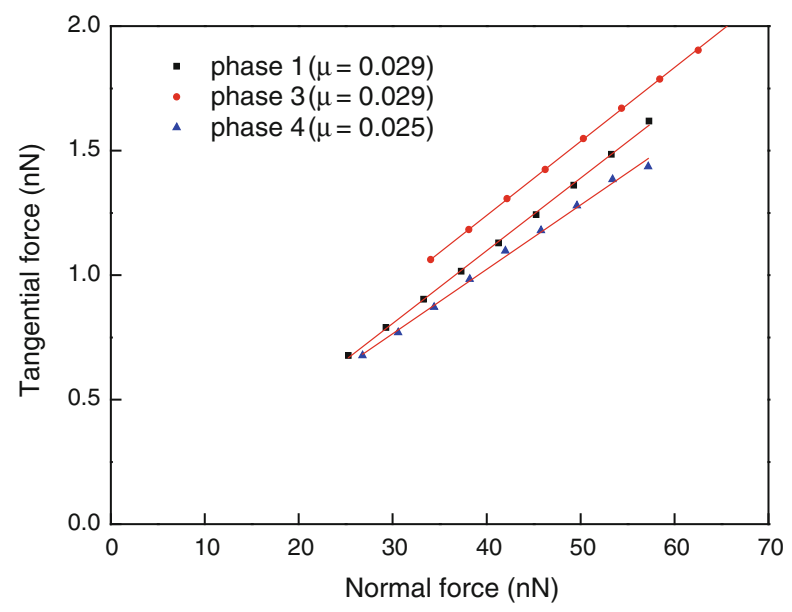

Fig. 6-Tangential force recorded by LFM on three different phases (Figs. 2(c), (e) and (f)) present in nanostructured FeCuAl-alumina coating.

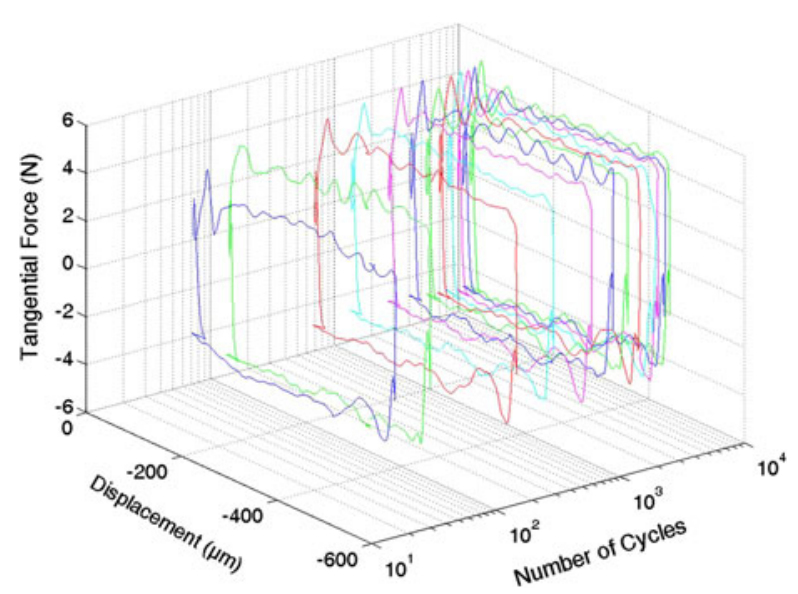

Fig. 7-Representative friction loop recorded on phases 3 (Fig. 2(e)) in nanostructured $\mathrm{FeCuAl}$-alumina coating measured by meso-tribometer.

coatings was taking place at any of the applied normal loads.

\section{E. Comparison of Friction from Nano- to Macro-Normal Loads}

The tangential forces recorded over a broad range of applied normal loads are summarized in Figure 8. Each inclined dashed line in the figure represents a line of constant coefficient of friction as postulated by Amontons' law. ${ }^{[24]}$ Open symbols indicate reciprocating sliding tests resulting in wear in the sliding contact. Closed symbols indicate reciprocating sliding tests without noticeable wear.

The coefficient of friction rises from 0.025 at nanoNewton normal loads up to 0.61 at Newton normal loads. Thus, a constant coefficient of friction for a given material couple is not noticed over the range of normal forces going from nano-Newtons to Newtons. At nano-Newton normal loads, each phase in the

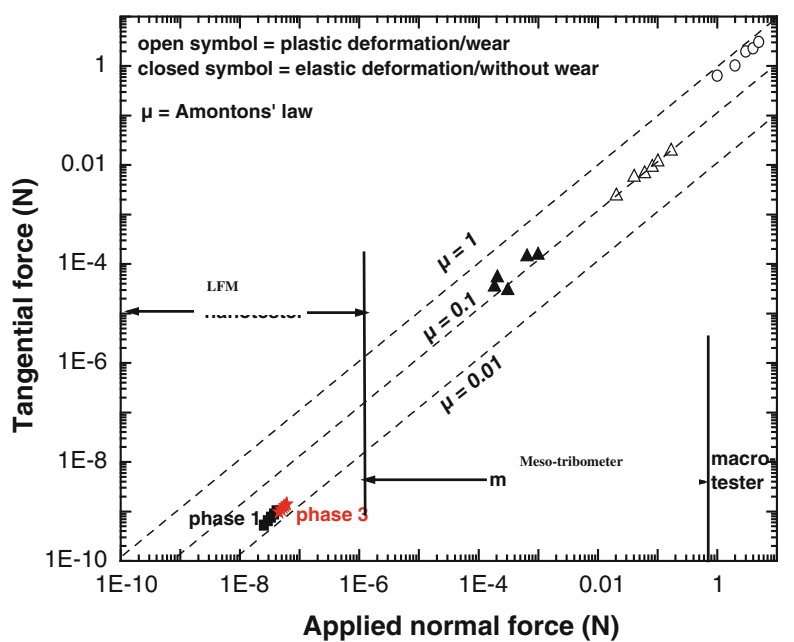

Fig. 8-Tangential force $v s$ applied normal force recorded on nanostructured $\mathrm{FeCuAl}$-alumina coating sliding against $\mathrm{Si}_{3} \mathrm{~N}_{4}$ ball. Dashed lines represent lines of constant coefficient of friction.

coating exhibits a different coefficient of friction, but all are very low $(\sim 0.029)$. It is important to note that, at this nano-normal load, the friction is greatly influenced by the roughness of the material. On increasing the normal load from milli- to macroNewtons, the coefficient of friction increases due to plastic deformation of the coating surface, and a plowing effect. ${ }^{[4]}$ Achanta et al. ${ }^{[27]}$ also reported the variation of coefficient of friction on wide normal load range on duplex steel and complex metallic alloys. At increasing normal load, the role of surface roughness and surface heterogeneity become less and less dominant. Indeed, it was reported by Buckley ${ }^{[28]}$ and Hutchings ${ }^{[29]}$ that plastic plowing contributes for most of the dissipated energy, leading to a higher friction force under such sliding conditions.

\section{F. Mechanical Properties of Different Phases by Nanoindentation}

To investigate the plastic-elastic behavior of different phases in the nanostructured FeCuAl-alumina coating, nanoindentation was carried out. A representative loading-unloading graph recorded on phase 3 (Figure 2(e)) is shown in Figure 9 along with SEM micrograph of the indentation imprint. The SEM investigation of the indentation site indicated that cracks did not form at the corners of the indentation marks. A comparison of nanohardness of the different phases and their respective coefficient of friction obtained by LFM, are shown in Figure 10. Phase 3 (Figure 2(e)) exhibits the lowest plastic-elastic ratio (Figure 9) and has the highest hardness among the four phases (Figure 10). An EDX investigation revealed that phase 3 contains about $73.57 \mathrm{wt}$ pct $(\mathrm{Al}+\mathrm{O})$ and 26.43 wt pct $(\mathrm{Fe}+\mathrm{Cu})($ Table I). As a result, this phase has a positive impact on wear resistance behavior of such coatings as reported earlier in Reference 4 and also exhibits the highest coefficient of friction among the four phases. 


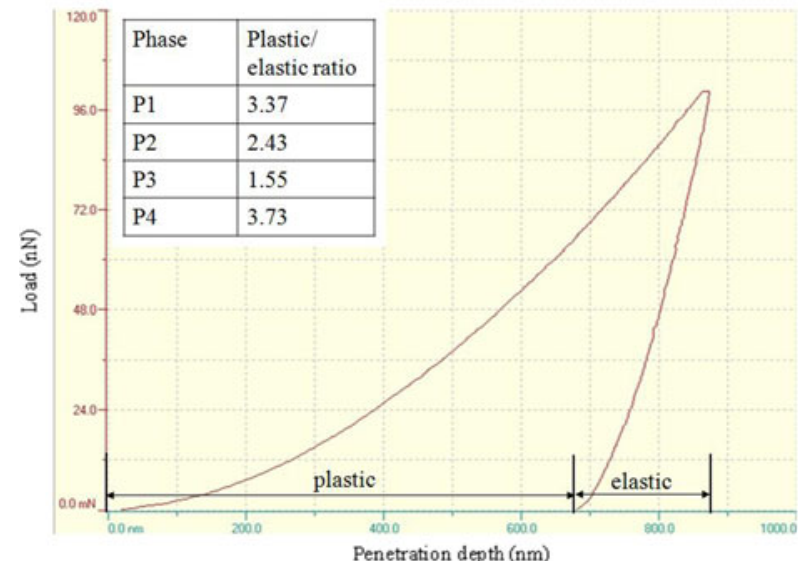

(a)

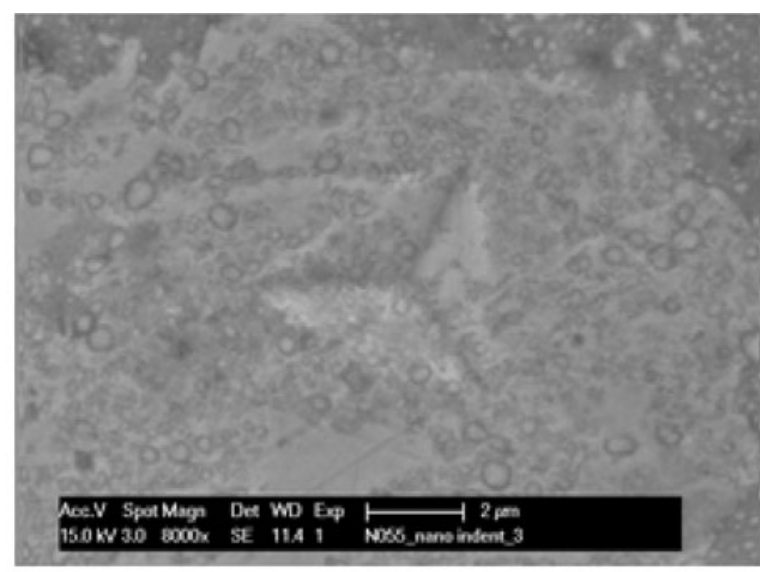

(b)

Fig. 9-Typical load-displacement graphs recorded on phase 1 (Fig. 2(c)) during nanoindentation (a), and corresponding SEM micrograph of the indent $(b){ }^{[4]}$

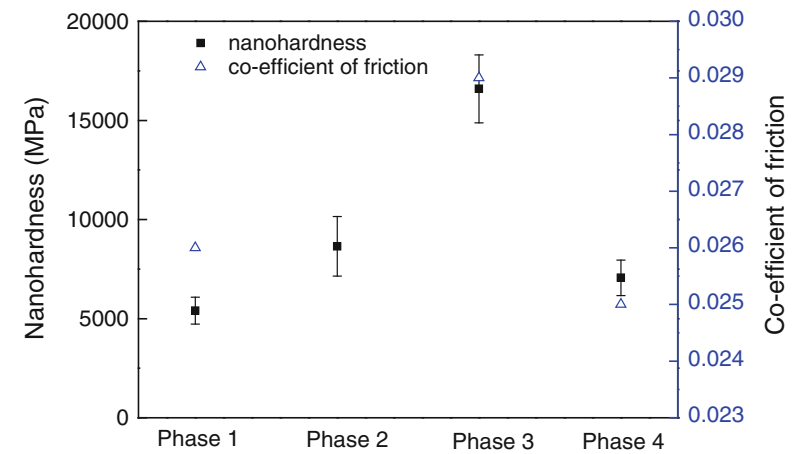

Fig. 10-Comparison of hardness and coefficient of friction of different phases (Figs. 2(c) to (f)) in nanostructured FeCuAl-alumina coatings.

\section{CONCLUSIONS}

Nanostructured FeCuAl-alumina coatings were successfully deposited by APS on low carbon steel substrates. Thought the initial feedstock was a mixture of metallic and ceramic powders, the coatings contain up to four different phases due to the high reactivity of the nanostructured powders. The friction behavior and mechanical properties of these different phases were determined by LFM measurements, reciprocating sliding tests in different tribometers, and finally nanoindentation. Three main conclusions can be derived from this investigation. The coefficient of friction under sliding conditions is not a constant over a wide normal force range, and it is not recommended to extrapolate the coefficient of friction recorded at nano-Newton to macro-Newton ranges, or vice versa. Secondly, the friction force increases with the applied normal force, but in a nonlinear way. Finally, the morphology of the different phases in nanostructured $\mathrm{FeCuAl}$-alumina coatings has a strong influence on the coefficient of friction at nano-normal loads, and that influence diminishes with increasing normal load due to different load accommodation mechanisms active at different normal load ranges.

\section{ACKNOWLEDGMENTS}

This work was done in the framework of a European GROWTH 2003 to 2006 project Nanospraying (contract G5RD-CT-2002-00862). A. K. Basak also acknowledges KU Leuven for providing a fellowship to carry out part of this work. Support by the WOG Scientific network of the Flemish FWO is also acknowledged.

\section{REFERENCES}

1. J. Karthikeyan, C.C. Berndt, J. Tikkanen, J.Y. Wang, and H. Herman: Nanostruct. Mater., 1997, vol. 8 (1), pp. 61-74.

2. V.L. Tellkamp, M.L. Lau, A. Fabel, and E.J. Lavernia: Nanostruct. Mater., 1997, vol. 9, pp. 489-92.

3. C.C. Berndt and E.J. Lavernia: J. Therm. Spray Technol., 1998, vol. 7 (3), pp. 411-41.

4. A.K. Basak, S. Achanta, J.P. Celis, M. Vardavoulias, and P. Matteazzi: Surf. Coat. Technol., 2008, vol. 202 (11), pp. 236873.

5. A.K. Basak, W. Zein Eddine, J.P. Celis, and P. Matteazzi: $J$. Nanosci. Nanotechnol., 2010, vol. 10 (2), pp. 1179-84.

6. B. Bhushan, J. Israelachvili, and U. Landman: Nature, 1995, vol. 374 , pp. $607-16$.

7. S. Achanta, D. Drees, J.P. Celis, O. Mollenhauer, and F. Spiller: Tribotest, 2004, vol. 11 (2), pp. 137-49.

8. H. Mohrbacher, J.P. Celis, and J.R. Roos: Tribol. Int., 1995, vol. 28 (5), pp. 269-78.

9. P. Matteazzi and M. Alcala: Mater. Sci. Eng. A, 1997, vol. 230, pp. 161-66.

10. A. K. Basak: PhD Thesis, Katholieke Universeteit Leuven, Belgium, 2009.

11. Digital Instruments Nanoscope III, AFM/LFM Instruction Manual, Section 10.1-10.6.

12. J.A. Ruan and B. Bhushan: Trans. ASME, 1994, vol. 116, pp. 378 88.

13. S. Fujisawa, E. Kishi, Y. Sugawara, and S. Morita: Appl. Phys. Lett., 1995, vol. 66 (4), pp. 526-29.

14. H. Butt, B. Cappella, and M. Kappl: Surf. Sci. Rep., 2005, vol. 59, pp. $1-152$. 
15. H. Hertz: J. Reine Angew. Math., 1881, vol. 92, pp. 156-71.

16. Z. Huq and J.-P. Celis: Wear, 2002, vol. 252, pp. 375-83.

17. S. Sundararajan and B. Bhushan: J. Appl. Phys., 2000, vol. 88, pp. $4825-31$.

18. R.M. Overney, E. Meyer, J. Frommer, D. Brodbeck, R. Luthi, L. Howald, H.-J. Guntherodt, M. Fujihira, H. Takano, and Y. Gotoh: Nature, 1992, vol. 359, pp. 133-35.

19. E. Gnecco, R. Bennewitz, A. Socoliuc, and E. Meyer: Wear, 2003, vol. 254, pp. 859-62.

20. J.A.Greenwood: Contact of Rough Surfaces, Fundamentals of Friction: Macroscopic and Microscopic Processes, I.L. Singer and H.M. Pollock, eds., Kluwer, Dordrecht, 1992, pp. $37-56$.

21. A. Berman, C. Drummond, and J. Israelachvili: Tribo. Lett., 1998, vol. 4, pp. 95-101.
22. L. Wenning and M.H. Muser: Europhys. Lett., 2001, vol. 54 (5), pp. 693-99.

23. S. Sundararajan and B. Bhushan: J. Vac. Sci. Technol. A, 2001, vol. 19, pp. 1777-85.

24. B.V.Z. Derjaguin: Physica, 1934, vol. 88, pp. 661-75.

25. Y.I. Rabonivich, J.J. Adler, M.S. Esayanur, A. Ata, R.K. Singh, and B.M. Moudgil: Adv. Colloid Interface. Sci., 2002, vol. 96, pp. 213-30.

26. X. Zhang and J.P. Celis: Appl. Surf. Sci., 2003, vol. 206, pp. 110 18.

27. S. Achanta and J.-P. Celis: Wear, 2010, vol. 269, pp. 435-42.

28. D.H. Buckley: Surface Effects in Adhesion, Friction, Wear and Lubrication, Elsevier, New York, 1981.

29. I.M. Hutchings: Tribology: Friction and Wear of Engineering Materials, Edward Arnold, London, 1992. 